\title{
Gene-nutrient interactions: dietary behaviour associated with high coronary heart disease risk particularly affects serum LDL cholesterol in apolipoprotein $\mathbf{E} \in 4$-carrying free-living individuals
}

\author{
Alexandre Loktionov*, Serena Scollen, Nicola McKeown and Sheila A. Bingham \\ Dunn Human Nutrition Unit, Wellcome Trust/MRC Building, Hills Road, Cambridge, CB2 2XY, UK
}

(Received 4 April 2000 - Revised 30 June 2000 - Accepted 21 July 2000)

\begin{abstract}
Apolipoprotein E (ApoE) genotype influence on the relationship between dietary risk factors for cardiovascular disease and blood serum lipid levels was investigated in 132 free-living individuals participating in the European Prospective Investigation of Cancer (EPIC) study. All subjects (age 40-69) were clinically healthy and provided information on their usual diet. ApoE genotype and serum lipid concentrations were determined in all subjects. Relationships of intake of dietary constituents with serum lipid levels were compared in different genotype groups. There was a significant correlation between total serum cholesterol and intake of energy derived from total fat $(r 0.195 ; P 0.025)$ and saturated fat $(r 0.174 ; P 0.046)$ in the cohort as a whole. However, individuals with the ApoE $\epsilon 3 / € 4$ genotype displayed a much stronger positive correlation between LDL cholesterol level and the percentage of energy derived from intake of saturated fat $(r 0.436 ; P 0.043)$. There were no significant associations in the groups with $\epsilon 3 / \epsilon 3$ or $\epsilon 2 / \epsilon 2 \& \epsilon 2 / \epsilon 3$ genotype. A significant positive correlation between alcohol consumption and HDL cholesterol level was present in individuals bearing ApoE $\epsilon 2$ allele. These findings support current public health recommendations that saturated fat consumption should be reduced in order to reduce coronary heart disease risk. Total cholesterol concentrations were positively related to saturated fat intake in the cohort as a whole, but elevated LDL cholesterol levels associated with high saturated fat intake can be expected particularly in those individuals who combine a 'risky' dietary behaviour with the presence of the $\epsilon 4$ variant of ApoE.
\end{abstract}

Genotype: Dietary fat: Serum cholesterol

The role of blood lipid concentrations, especially elevated levels of LDL cholesterol and decreased levels of HDL cholesterol, in the development of coronary heart disease is now well documented (Castelli et al. 1986; Castelli, 1996). Population comparisons and metabolic trials have consistently shown associations between dietary cholesterol and saturated fat intake and serum lipid concentrations (McGill, 1979; LaRosa et al. 1990; Clarke et al. 1997). However, no study of free-living individuals has confirmed these findings until now. This may be due to the effect of other dietary factors, intra-individual variation in diet and blood cholesterol from day to day, and large inter-individual variation in regulation of lipid metabolism resulting from genetic polymorphisms present in human populations. The identification of interactions between genetic background and modifiable dietary factors affecting lipid metabolism has however been little explored in large epidemiological trials.

Apolipoprotein E (ApoE) gene polymorphism involving codons 112 and 158 is a major determinant of blood lipid levels in humans (Wilson et al. 1994, Castelli, 1996). ApoE allele distribution shows similar patterns in most Caucasian populations. Allele $\epsilon 3$ (Cys112; Arg158) is the most common one with frequencies between 0.70 and $0.85, \epsilon 4$ (Arg112; Arg158) is less frequent $(0 \cdot 10-0 \cdot 20)$ and $\epsilon 2$ (Cys112; Cys158) is the rarest one at 0.05-0.10 (Hallman et al. 1991; Corbo \& Scacchi, 1999; Loktionov et al. 1999). The ApoE protein acts as the ligand between lipoprotein particles and hepatic LDL and chylomicron receptors, and the properties of the two binding domains of the protein molecule differ in the variants encoded by the three alleles resulting in their functional differences (Weisgraber \&

\footnotetext{
Abbreviation: ApoE, apolipoprotein E.

* Corresponding author: Dr A. Loktionov, fax +44(0)1223 252765, email alex.loktionov@mrc-dunn.cam.ac.uk
} 
Mahley, 1996). The presence of the apolipoprotein $E \in 4$ allele associated with increased levels of total and LDL serum cholesterol is now considered as being an important coronary heart disease risk factor (Wilson et al. 1994, 1996; Castelli, 1996). Some intervention studies have demonstrated that individuals bearing the $\epsilon 4$ variant are more likely to respond to increased dietary intake of fat and cholesterol with elevation of both total and LDL serum cholesterol levels (Tikkanen et al. 1990; Gylling \& Miettinen, 1992; Dreon et al. 1995; Sarkkinen et al. 1998), but other groups failed to observe any difference (Savolainen et al. 1991; Pasagian-Macaulay et al. 1997). These discrepancies may be at least partially attributed to different study designs and diets applied. The ApoE genotype effect on dietary modulation of serum lipid levels has not hitherto been investigated in free-living populations unlimited in composition of their diets.

In the present study we have examined interactions between consumption of dietary constituents and serum lipid levels in relation to ApoE genotypes in a free-living cohort of participants of the European Prospective Investigation of Cancer (EPIC) study (Day et al. 1999).

\section{Methods}

\section{Subjects}

The subjects participated in the European Prospective Investigation of Cancer (EPIC) study (Day et al. 1999). This is a large free-living cohort of about 25000 people from Norfolk, UK. As part of quality control studies on dietary methods used in the main cohort, 132 clinically healthy subjects (sixty males, seventy-two females, all Caucasians, age 40-69 years) were recruited and investigated in the present study. There were eighteen moderate smokers and 114 non-smokers among them. Dietary information was available for the subjects from Food Frequency Questionnaires (Day et al. 1999). Ethical permission for the EPIC study was given by the Norwich District Ethics Committee in 1992, and for the subsequent studies reported here in 1996 and 1999.

\section{Blood collection and analysis}

Subjects in the study gave three $10 \mathrm{ml}$ blood samples after a $12 \mathrm{~h}$ fast at 3-month intervals. Serum and cell fractions (buffy coats) were separated by centrifugation. Genomic DNA was extracted from buffy coats. Serum was stored at $-20^{\circ} \mathrm{C}$ prior to analysis for total cholesterol, LDL cholesterol, HDL cholesterol and triacylglycerols. Serum lipid measurements were performed as earlier reported (Loktionov et al. 1998), and the average of the three measures used in the present analysis.

\section{Genotype determination}

Genomic DNA was used for ApoE genotype determination. It was performed in all 132 subjects using a modification of the protocol based on $\mathrm{HhaI}$ restriction fragment length polymorphism detection. The detailed genotyping procedure has been described elsewhere (Loktionov et al. 1998).

\section{Statistics}

All results were expressed as the mean and standard error. Unpaired $t$ tests were carried out to compare parameters between different genotype groups. Pearson correlation coefficients and simple linear regression between intake of different dietary constituents and serum lipid concentrations were also calculated. In some cases multiple regression analysis was employed to assess influence of confounding factors including age, gender, body mass index, and smoking status. Systat 5.2 (Systat, Evanston IL, USA) and Data Desk ${ }^{4}$ (Data Description, Inc., Ithaca, NY, USA) statistical packages were used for statistical analyses.

\section{Results \\ ApoE genotype and allele distribution}

All three common ApoE alleles were found among the study subjects. The following genotype frequencies were observed: $\epsilon 2 / \epsilon 2 \quad 0.8 \%$ (one female); $\epsilon 2 / \epsilon 3 \quad 14.4 \%$ (nine males and ten females); $\epsilon 2 / \epsilon 43.0 \%$ (one male and three females); $\epsilon 3 / \epsilon 3 \quad 64.4 \%$ (thirty-nine males and forty-six females); $\epsilon 3 / \epsilon 417.4 \%$ (eleven males and twelve females). No $\epsilon 4 / \epsilon 4$ homozygotes were found. The allele distribution with $9.5 \%$ of $\epsilon 2,80.3 \%$ of $\epsilon 3$, and $10.2 \%$ of $\epsilon 4$ was within the range common for Caucasian populations. It is accepted that phenotypic effects of $\epsilon 2$ and $\epsilon 4$ alleles are manifested in $\epsilon 2 / \epsilon 3$ and $\epsilon 3 / \epsilon 4$ heterozygotes, so we regarded these variants as $\epsilon 2$ - and $\epsilon 4$-expressing respectively. There is a view that the $\mathrm{ApoE} \epsilon 2$ allele is a dominant one in any combination (Bohnet et al. 1996). Nevertheless, we treated subjects with the $\epsilon 2 / \epsilon 4$ genotype as a separate small group since the absence of interference of opposite effects of the $\epsilon 2$ and $\epsilon 4$ on lipid levels is still not proven.

\section{ApoE genotype, serum lipids and diet}

Serum lipid levels for different genotype groups are shown in Table 1. As expected, comparison between the three most common ApoE variants demonstrated slightly lower concentrations of total and LDL cholesterol in the $\epsilon 2$ expressing subjects, whereas $\epsilon 3$ - and $\epsilon 4$-expressing groups displayed generally higher values. It was difficult to interpret high serum lipid levels in the $\epsilon 2 / \epsilon 4$ group since there were only four individuals in it; however obviously higher consumption of fat found in this small group (see Table 2) could be a contributing factor. Higher triacylglycerol concentrations were observed in the $\epsilon 4$ group. No significant differences $(P<0.05)$ between the sexes in total and LDL cholesterol levels were found, whereas significant differences $(P<0.05)$ existed between the sexes in HDL cholesterol and triacylglycerol concentrations among $\epsilon 3$ and $\epsilon 4$ group subjects, females displaying significantly higher HDL cholesterol and lower triacylglycerol levels $(P<0 \cdot 05)$. There was no significant difference $(P<0.05)$ in age distributions and body mass index values between genotype groups (Table 1). Comparisons of average intake of dietary constituents did not reveal any significant differences $(P<0.05)$ between three main ApoE genotype groups (Table 2). 
Table 1. Comparison of age, body mass index, and serum lipid concentrations in free-living subjects with different ApoE genotypes (Data are means and standard errors)

\begin{tabular}{|c|c|c|c|c|c|c|c|c|c|c|c|c|c|}
\hline \multirow[b]{2}{*}{ ApoE Genotype } & \multirow{2}{*}{$\begin{array}{l}\text { Number } \\
\text { of } \\
\text { subjects }\end{array}$} & \multicolumn{2}{|c|}{$\begin{array}{c}\text { Age } \\
\text { (Years) }\end{array}$} & \multicolumn{2}{|c|}{$\begin{array}{c}\mathrm{BMl} \\
\left(\mathrm{kg} / \mathrm{m}^{2}\right)\end{array}$} & \multicolumn{2}{|c|}{$\begin{array}{l}\text { Total cholesterol } \\
(\mathrm{mmol} / \mathrm{l})\end{array}$} & \multicolumn{2}{|c|}{$\begin{array}{l}\text { LDL cholesterol } \\
\quad(\mathrm{mmol} / \mathrm{l})\end{array}$} & \multicolumn{2}{|c|}{$\begin{array}{l}\mathrm{HDL} \text { cholesterol } \\
(\mathrm{mmol} / \mathrm{l})\end{array}$} & \multicolumn{2}{|c|}{$\begin{array}{l}\text { Triacylglycerols } \\
(\mathrm{mmol} / \mathrm{l})\end{array}$} \\
\hline & & Mean & SE & Mean & SE & Mean & SE & Mean & SE & Mean & SE & Mean & SE \\
\hline All types & 132 & $53 \cdot 6$ & 1.5 & $26 \cdot 2$ & 0.6 & 6.09 & 0.20 & 4.05 & 0.19 & $1 \cdot 35$ & 0.07 & $1 \cdot 80$ & 0.17 \\
\hline Males & 60 & 53.7 & $2 \cdot 1$ & $27 \cdot 1$ & 0.9 & $6 \cdot 21$ & 0.26 & $4 \cdot 19$ & 0.23 & $1 \cdot 18^{d}$ & 0.08 & $2 \cdot 12^{\mathrm{g}}$ & 0.29 \\
\hline Females & 72 & 53.5 & $2 \cdot 1$ & $25 \cdot 5$ & $1 \cdot 0$ & $5 \cdot 99$ & 0.30 & 3.93 & 0.29 & $1.50^{\mathrm{d}}$ & 0.10 & $1.53^{\mathrm{g}}$ & 0.19 \\
\hline$\epsilon 2$-expressing $(\epsilon 2 / \epsilon 2 \& \in 2 / \epsilon 3)$ & 20 & $55 \cdot 8$ & 4.9 & $27 \cdot 4$ & 1.7 & $5 \cdot 63^{a}$ & 0.48 & 3.62 & 0.54 & 1.35 & 0.19 & 1.90 & 0.44 \\
\hline Males & 9 & $55 \cdot 1$ & 6.5 & $26 \cdot 7$ & $2 \cdot 3$ & $5 \cdot 41^{\mathrm{b}}$ & 0.50 & $3 \cdot 50^{\mathrm{c}}$ & 0.45 & 1.25 & 0.19 & 1.90 & 0.66 \\
\hline Females & 11 & $56 \cdot 4$ & $9 \cdot 1$ & $28 \cdot 1$ & $3 \cdot 2$ & $5 \cdot 82$ & 0.82 & 3.72 & 1.00 & 1.42 & 0.36 & $1.90^{\mathrm{h}}$ & 0.71 \\
\hline$\epsilon 3$-expressing $(\epsilon 3 / \epsilon 3)$ & 85 & 53.2 & 1.9 & $26 \cdot 0$ & 0.8 & $6 \cdot 11$ & 0.24 & 4.13 & 0.24 & 1.36 & 0.09 & $1.64^{i}$ & 0.19 \\
\hline Males & 39 & 53.4 & $2 \cdot 8$ & $26 \cdot 8$ & $1 \cdot 2$ & $6 \cdot 33^{b}$ & 0.28 & $4 \cdot 35^{\mathrm{c}}$ & 0.29 & $1 \cdot 20^{\mathrm{e}}$ & 0.11 & $1.97^{\mathrm{j}, \mathrm{k}}$ & 0.32 \\
\hline Females & 46 & 53.0 & $2 \cdot 6$ & $25 \cdot 3$ & 1.2 & $5 \cdot 93$ & 0.38 & 3.94 & 0.35 & $1.49^{\mathrm{e}}$ & 0.13 & $1.35^{\mathrm{h}, \mathrm{k}}$ & 0.20 \\
\hline$\epsilon 4$-expressing $(\epsilon 3 / \epsilon 4)$ & 23 & $53 \cdot 3$ & $2 \cdot 8$ & $25 \cdot 9$ & 1.4 & $6 \cdot 24$ & 0.49 & $4 \cdot 11$ & 0.49 & 1.33 & 0.16 & $2 \cdot 24^{i}$ & 0.60 \\
\hline Males & 11 & 53.3 & 3.7 & $28 \cdot 1$ & 1.6 & $6 \cdot 21$ & 0.71 & $4 \cdot 18$ & 0.64 & $1.07^{f}$ & $0 \cdot 10$ & $2 \cdot 84^{\mathrm{j}, \mathrm{I}}$ & 1.06 \\
\hline Females & 12 & 53.3 & 4.6 & 23.9 & $2 \cdot 2$ & $6 \cdot 26$ & 0.79 & 4.06 & 0.80 & $1.56^{f}$ & 0.21 & $1.70^{1}$ & 0.55 \\
\hline$\epsilon 2 / \epsilon 4$ combination* & 4 & 53.5 & $9 \cdot 2$ & 27.5 & $9 \cdot 3$ & $7 \cdot 14^{a}$ & $2 \cdot 15$ & 4.22 & 0.41 & 1.51 & 0.79 & $2 \cdot 16$ & 1.68 \\
\hline
\end{tabular}

* Limited number of subjects in this group prevented us from analysing males and females separately.

${ }^{\text {a }} P 0.0174 ;{ }^{\mathrm{b}} P 0.0039 ;{ }^{\mathrm{c}} P 0.0084 ;{ }^{\mathrm{d}} P<0.0001 ;{ }^{\mathrm{e}} P 0.0017 ;{ }^{\mathrm{f}} P 0.0002 ;{ }^{\mathrm{g}} P 0.0007 ;{ }^{\mathrm{h}} P 0.0315 ;{ }^{\mathrm{i}} P 0.0060 ;{ }^{\mathrm{j}} P 0.0017 ;{ }^{\mathrm{k}} P 0.0002 ;{ }^{1} P 0.0007$. Letters indicate pair-wise comparisons between genotype groups or between males and females within genotype groups.

Interaction between dietary constituents and serum lipids in subjects with different ApoE genotypes

In the cohort as a whole there were weak but significant positive correlations between total serum cholesterol and daily intake of dietary constituents including total energy ( $r$ 0.173, $P 0.047)$, total fat $(r 0.219, P 0.012)$, saturated fat ( $r$ 0.216, $P$ 0.013), monounsaturated fat $(r 0 \cdot 216, P 0 \cdot 013)$, polyunsaturated fat $(r 0 \cdot 197, P 0 \cdot 023)$, cholesterol $(r 0 \cdot 195$, $P 0.025)$ and total protein $(r 0 \cdot 180, P 0 \cdot 039)$. This effect, however, disappeared for protein and polyunsaturated fat when expressing the contribution of nutrients as a percentage of total energy intakes. It was still present for total fat as energy $\%(r 0 \cdot 195, P 0 \cdot 025)$, saturated fat as energy $\%(r 0.174, P 0 \cdot 046)$, and monounsaturated fat as energy $\%(r 0 \cdot 181, P 0 \cdot 038)$. Multiple regression analysis incorporating influences of age, gender, body mass index and smoking revealed that only influence of total fat intake was still statistically significant $(P$ 0.028). No marked relationships between diet and concentrations of LDL cholesterol, HDL cholesterol, and triacylglycerols were found.

ApoE genotype variants were then analysed separately. There were no significant correlations between dietary factors and serum lipids in the $\epsilon 2$ and $\epsilon 3$ groups apart from a positive association of alcohol intake with HDL cholesterol in the $\epsilon 2$ group $(r 0.563, P 0.010)$. Negative correlations between alcohol intake and total cholesterol, LDL cholesterol and triacylglycerols were also present in this group, but they were not statistically significant.

In the $\epsilon 4$-expressing subjects, positive correlations between diet and blood lipids were found for total fat

Table 2. Daily intake of main dietary constituents calculated from food questionnaires in free-living subjects with different ApoE genotypes (Data are means and standard errors)

\begin{tabular}{|c|c|c|c|c|c|c|c|c|c|c|}
\hline \multirow[b]{3}{*}{ Dietary constituents } & & & \multicolumn{8}{|c|}{ ApoE genotype groups } \\
\hline & \multicolumn{2}{|c|}{$\begin{array}{l}\text { All subjects } \\
(\epsilon 2 / \epsilon 2 \& \epsilon 2 / \epsilon 3)\end{array}$} & \multicolumn{2}{|c|}{$\begin{array}{c}\epsilon 2-\text { expressing } \\
(\epsilon 3 / \epsilon 3)\end{array}$} & \multicolumn{2}{|c|}{$\begin{array}{c}\epsilon 3 \text {-expressing } \\
(\in 3 / € 4)\end{array}$} & \multicolumn{2}{|c|}{$\begin{array}{l}\epsilon 4 \text {-expressing } \\
\text { combination }\end{array}$} & \multicolumn{2}{|c|}{$\epsilon 2 / \epsilon 4$} \\
\hline & Mean & SE & Mean & SE & Mean & SE & Mean & SE & Mean & SE \\
\hline Energy (kJ) & 8760 & 258 & 9193 & 813 & 8631 & 321 & 8691 & 471 & 9749 & 1818 \\
\hline Total fat $(\mathrm{g})$ & $81 \cdot 1$ & $3 \cdot 3$ & $82 \cdot 1$ & $9 \cdot 8$ & 80.4 & $4 \cdot 2$ & $78 \cdot 6$ & $6 \cdot 2$ & $106 \cdot 5$ & $20 \cdot 4$ \\
\hline Total fat (energy \%) & $33 \cdot 2$ & 0.6 & $31 \cdot 7^{\mathrm{a}}$ & $7 \cdot 1$ & $33 \cdot 2$ & 0.8 & $33 \cdot 0$ & 1.5 & $40 \cdot 0^{a}$ & $3 \cdot 0$ \\
\hline Monounsaturated fat $(\mathrm{g})$ & $28 \cdot 7$ & $1 \cdot 2$ & $29 \cdot 2$ & 3.5 & $28 \cdot 3$ & $1 \cdot 6$ & $27 \cdot 3$ & $2 \cdot 2$ & $39 \cdot 6$ & $8 \cdot 1$ \\
\hline Monounsaturated fat (energy \%) & $11 \cdot 7$ & $0 . \overline{3}$ & $11 \cdot 3^{b}$ & 0.6 & $11 \cdot 6^{\mathrm{c}}$ & 0.3 & $11 \cdot 4^{d}$ & 0.5 & $14 \cdot 9^{b, c, d}$ & $1 \cdot 8$ \\
\hline Polyunsaturated fat (g) & $14 \cdot 1$ & $1 \cdot 2$ & $13 \cdot 0$ & $1 \cdot 4$ & $14 \cdot 4$ & 0.8 & $13 \cdot 3$ & $1 \cdot 0$ & $18 \cdot 7$ & $6 \cdot 1$ \\
\hline Polyunsaturated fat (energy \%) & 5.9 & 0.2 & $5 \cdot 2$ & 0.3 & $6 \cdot 0$ & 0.2 & 5.7 & 0.4 & 6.5 & $1 \cdot 2$ \\
\hline Saturated fat $(g)$ & $31 \cdot 8$ & 1.4 & $33 \cdot 0$ & 4.5 & $31 \cdot 1$ & $1 \cdot 8$ & 31.7 & 2.9 & 41.9 & $5 \cdot 7$ \\
\hline Saturated fat (energy \%) & $12 \cdot 9$ & 0.4 & $12 \cdot 5$ & 0.9 & $12 \cdot 8$ & 0.4 & $13 \cdot 2$ & 0.8 & $16 \cdot 5$ & 1.4 \\
\hline Cholesterol (mg) & 297.9 & $12 \cdot 9$ & $341 \cdot 2$ & $45 \cdot 8$ & $280 \cdot 3$ & $14 \cdot 8$ & $310 \cdot 4$ & $25 \cdot 4$ & 385.4 & 88.9 \\
\hline Protein $(\mathrm{g})$ & 86.4 & $2 \cdot 2$ & $92 \cdot 3$ & 5.4 & 84.4 & $3 \cdot 0$ & 88.4 & 4.4 & $87 \cdot 8$ & $14 \cdot 2$ \\
\hline Protein (energy \%) & $17 \cdot 3$ & 0.3 & $18 \cdot 2$ & 0.8 & $17 \cdot 1$ & 0.4 & $17 \cdot 5$ & 0.5 & $15 \cdot 6$ & 0.8 \\
\hline Carbohydrates $(\mathrm{g})^{\prime}$ & 253.9 & $7 \cdot 5$ & $268 \cdot 0$ & $23 \cdot 0$ & $251 \cdot 1$ & $9 \cdot 4$ & $250 \cdot 9$ & $14 \cdot 2$ & $259 \cdot 9$ & $48 \cdot 9$ \\
\hline Carbohydrates (energy \%) & $46 \cdot 9$ & 0.6 & $47 \cdot 4$ & $1 \cdot 7$ & $47 \cdot 1$ & 0.8 & $46 \cdot 5$ & 1.4 & $43 \cdot 2$ & $2 \cdot 3$ \\
\hline Alcohol $(g)$ & 7.9 & 0.9 & $10 \cdot 3$ & $3 \cdot 6$ & $7 \cdot 1$ & 0.9 & $9 \cdot 2$ & 2.5 & 5.5 & 4.7 \\
\hline Alcohol (energy \%) & $2 \cdot 6$ & 0.3 & 2.7 & 0.8 & 2.5 & 0.4 & $3 \cdot 0$ & 0.7 & $1 \cdot 2$ & 1.0 \\
\hline
\end{tabular}

\footnotetext{
${ }^{\mathrm{a}} P$ 0.0493; ${ }^{\mathrm{b}} P 0.0296 ;{ }^{\mathrm{c}} P 0.0381 ;{ }^{\mathrm{d}} P 0.0408$. All these values fail to reach statistical significance if Bonferroni correction is applied.
} 

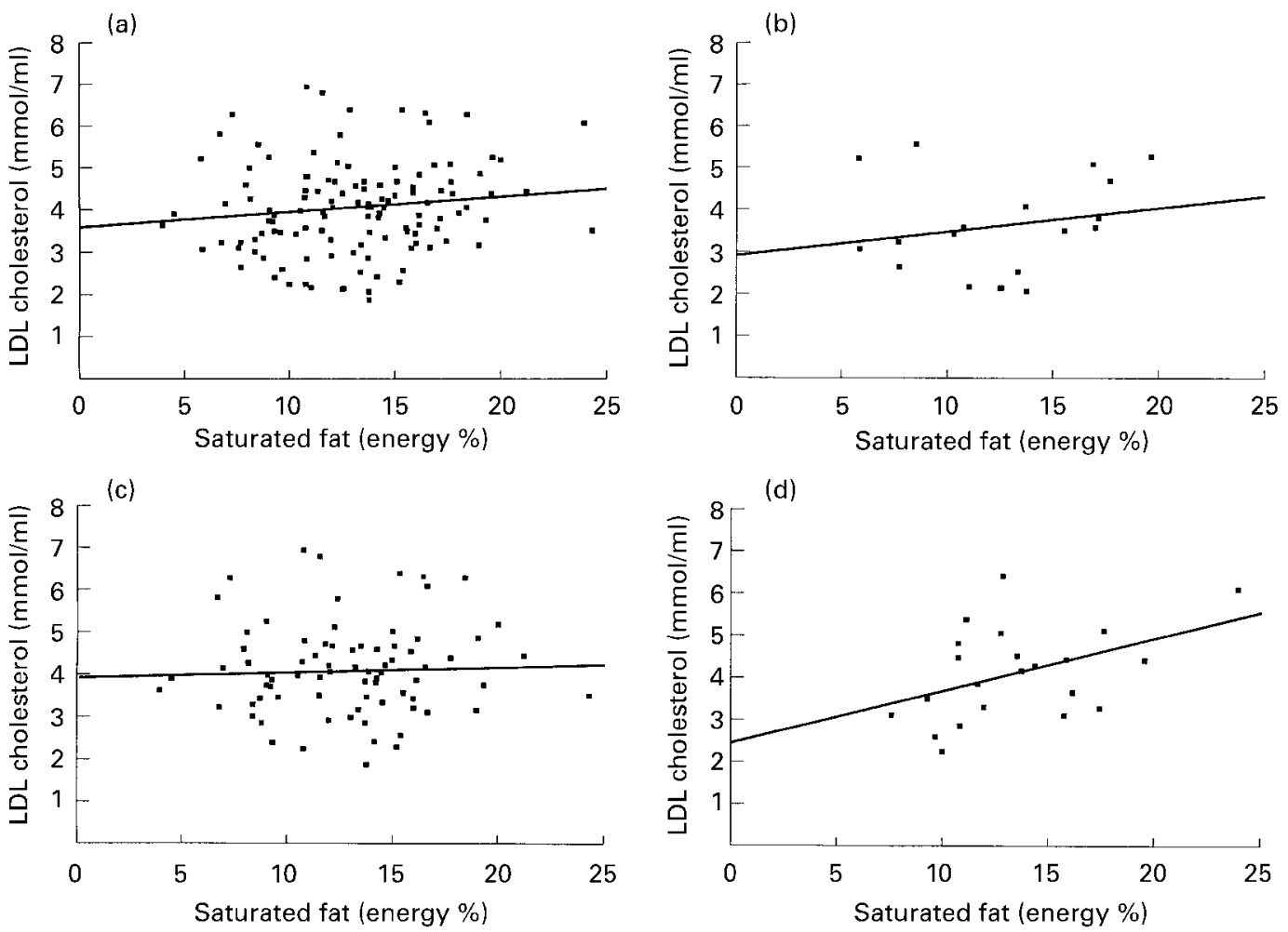

Fig. 1. Scatterplots of LDL cholesterol serum levels and energy percent provided by daily intake of saturated fatty acids (SF) with the corresponding regression lines showing: (a) All 132 study subjects. Regression line corresponds to: $\mathrm{LDL}=0.038 \times \mathrm{SF}+3.552(P=0.119)$. (b) Twenty individuals bearing ApoE $\epsilon 2$ allele $(\epsilon 2 / \epsilon 2 \& \epsilon 2 / \epsilon 3$ genotypes). Regression line corresponds to: $\mathrm{LDL}=0.057 \times \mathrm{SF}+2.906(P=0.401)$. (c) Eighty-five individuals with ApoE $\epsilon 3 / \epsilon 3$ genotype. Regression line corresponds to: $\mathrm{LDL}=0.011 \times \mathrm{SF}+3.984 ;(P=0.718)$. (d) Twenty-three individuals with ApoE $\in 3 / \epsilon 4$ genotype. Regression line corresponds to: $\mathrm{LDL}=0.123 \times \mathrm{SF}+2.447(P=0.043)$

intake and total and LDL cholesterol $(r 0.422, P 0.045$ and $r$ 0.494, $P$ 0.016 respectively) and for saturated fat intake and total and LDL cholesterol $(r 0.479, P 0.021$ and $r 0.565$, $P 0.006$ respectively). Monounsaturated fat consumption was also positively correlated with total and LDL cholesterol concentrations $(r 0.419, P 0.047$ and $r 0.453$, $P 0.034$ respectively), whereas it was inversely related with HDL cholesterol $(r-0.413, P$ 0.050). There were also inverse associations between HDL cholesterol and polyunsaturated fat $(r-0.504, P 0.014)$ and protein $(r-0.421$, $P$ 0.045). Alcohol intake was positively correlated with triacylglycerol concentration $(r 0.460, P 0 \cdot 027)$. There were also positive associations between energy intake and serum lipids for total cholesterol $(r$ 0.447, $P$ 0.033) and LDL cholesterol ( $r$ 0.475, $P$ 0.026), and a negative association for HDL cholesterol $(r-0.482, P$ 0.046). However, when energy was controlled for by expressing intakes as a percentage of total energy, only the relation between saturated fat and LDL cholesterol remained significant ( $r$ 0.436, $P$ 0.043). This relationship was even stronger in multiple regression controlling for age, gender, body mass index and smoking status ( $P$ 0.006). Fig. 1 shows scatterplots with regression lines demonstrating the relationship between saturated fat intake as a percentage of total energy and LDL cholesterol concentration in the individuals with different genotypes. There is a convincing relationship only in the $\epsilon 4$ individuals. The LDL cholesterol serum concentration in this group changed by
$0.123 \mathrm{mmol} / \mathrm{l}$ for every $1 \%$ of change in energy provided by saturated fat. Comparison of the genotype groups by multiple regression analysis revealed a highly significant difference $\left(\begin{array}{ll}P & 0.005\end{array}\right)$ between $\epsilon 3$ - and $\epsilon 4$-expressing individuals when age, gender, BMI and smoking status were taken into account.

\section{Discussion}

Atherosclerosis and coronary heart disease pathogenesis incorporates numerous interacting mechanisms, undergoing regulation by both intrinsic (genetic) and modifiable (environmental and life-style) factors (Ross, 1993). Our findings of a significant relation between total and saturated fat consumption and total and LDL cholesterol presented in this paper support current public health recommendations that saturated fat consumption should be reduced to $10 \%$ total energy in the population as a whole in order to reduce the currently high serum LDL and total cholesterol levels in the UK (COMA 1991, 1994). However we observed differential responses according to the ApoE genotype, and individuals expressing both the $\epsilon 2$ and the $\epsilon 3$ variants of the gene did not display any substantial diet-dependent changes in their serum lipid levels, suggesting that homeostatic mechanisms controlling lipid distribution and metabolism act efficiently in these people.

The presence of the ApoE $\epsilon 4$ allele seems to damage this 
mechanism so that the serum lipid concentrations become more dependent on dietary factors in the affected subjects. This observation provides further evidence corroborating the $\epsilon 4$ allele presence as an important coronary heart disease risk factor. When controlling for energy expenditure and body size by expressing results as a percentage of total energy intake, there was a much stronger and direct relationship between dietary saturated fat and LDL cholesterol levels in these people. This implies that individuals with this genotype and serum lipid patterns that are unfavourable for coronary heart disease may be able to respond to dietary interventions to a greater extent compared to similar persons with other ApoE variants. Indeed, simple calculations show that in these subjects a $50 \%$ change in saturated fat consumption would result in almost $20 \%$ change in LDL cholesterol serum level. In contrast, if the whole cohort were taken, regardless of genotypes, a $50 \%$ change in saturated fat intake would result only in approximately $5 \%$ changes in both total and LDL cholesterol levels.

Light to moderate alcohol consumption is now widely regarded as a protective factor against coronary heart disease risk (Thun et al. 1997; Muntwyler et al. 1998; Berger et al. 1999). Several groups earlier reported alcoholinduced decrease in total cholesterol, LDL cholesterol and triacylglycerol levels and simultaneous increase in HDL cholesterol concentration (Linn et al. 1993; Mayer et al. 1993; Choudhury et al. 1994). However, alcohol raises blood pressure at intakes above about 4 units per day increasing the risk of stroke (COMA, 1991, 1994). Our data also indicate that people with different ApoE allele combinations are likely to respond differently to alcohol intake. The 'protective' pattern of serum lipid level changes related to moderate alcohol consumption was manifested in the $\epsilon 2$-bearing subjects and less pronounced in the $\epsilon 3 / \epsilon 3$ majority. In contrast, in the $\epsilon 4$ group alcohol was associated with increased serum triacylglycerols, although raised serum triacylglycerol levels are a less clearly defined risk factor for coronary heart disease (Patsch, 1993; Harjai, 1999). The observation is again consistent with the fact of greater coronary heart disease risk associated with the presence of the $\epsilon 4$ allele. These results, however, need confirmation in a larger cohort since about $25 \%$ of the participants of the present study either completely abstained from alcohol or reported occasional intake of very low amounts.

This study has demonstrated the importance of assessing gene-nutrient interactions in strengthening the evidence relating diet to cardiovascular disease risk. Unlike previous studies, these associations have been found in a free-living population. However, members of the general public are unlikely to have the opportunity at present to be genotyped for ApoE. In the absence of population-based genotyping facilities, current advice for the population, as a whole to restrict saturated fat consumption in order to reduce the risk of coronary heart disease should be followed.

\section{Acknowledgements}

We are grateful to all participants and general practitioners who have helped with this study, and to the nurses, technicians and the staff of the EPIC coordinating centre. Undergraduate students from Coleraine, Surrey, Wageningen, and London Universities and Leeds Polytechnic assisted with the collection and interpretation of the field work. We are also indebted to Professor N. E. Day and Professor K. T. Khaw for their useful comments on the manuscript. The EPIC Norfolk Study is funded by the Cancer Research Campaign, the Medical Research Council, the British Heart Foundation, the Ministry of Agriculture Fisheries and Food, the Department of Health, and the Europe Against Cancer Programme of the Commission of the European Communities.

\section{References}

Berger K, Adjani UA, Kase C, Gaziano JM, Buring JE, Glynn RJ \& Hennekens CH (1999) Light-to-moderate alcohol consumption and the risk of stroke among US male physicians. New England Journal of Medicine 341, 1557-1564.

Bohnet K, Regis-Bailly A, Vincent-Viry M, Schlenck A, Gueguen R, Siest G \& Visvikis S (1996) Apolipoprotein E genotype $\epsilon 4 / \epsilon 2$ in the STANISLAS cohort study - dominance of the $\epsilon 2$ allele? Annals of Human Genetics 60, 509-516.

Castelli WP (1996) Lipids, risk factors and ischaemic heart disease. Atherosclerosis 124, Suppl., S1-S9.

Castelli WP, Garrison RJ, Wilson PWF, Abbott RD, Kalousdian S \& Kannel WB (1986) Incidence of coronary heart disease and lipoprotein cholesterol levels: the Framingham study. JAMA 256, 2835-2838.

Choudhury SR, Ueshima H, Kita Y, Kobayashi KM, Okayama A, Yamakawa M, Hirao Y, Ishikawa M \& Miyoshi Y (1994) Alcohol intake and serum lipids in a Japanese population. International Journal of Epidemiology 23, 940-947.

Clarke R, Frost C, Collins R, Appleby P \& Peto R (1997) Dietary lipids and blood cholesterol: quantitative meta-analysis of metabolic ward studies. British Medical Journal 314, 112-117.

Corbo RM \& Scacchi R (1999) Apolipoprotein E (APOE) allele distribution in the world. Is APOE*4 a 'thirty' allele? Annals of Human Genetics 63, 301-310.

Day NE, Oakes S, Luben R, Khaw KT, Bingham S, Welch A \& Wareham N (1999) EPIC in Norfolk: Study Design and Characteristics of the Cohort. British Journal of Cancer $\mathbf{8 0}$, Suppl. 1, 95-103.

Dreon DM, Fernstrom HA, Miller B \& Krauss RM (1995) Apolipoprotein E isoform phenotype and LDL subclass response to a reduced-fat diet. Arteriosclerosis, Thrombosis and Vascular Biology 16, 105-111.

Gylling H \& Miettinen T (1992) Cholesterol absorption and synthesis related to low density lipoprotein metabolism during varying cholesterol intake in men with different apoE phenotype. Journal of Lipid Research 33, 1361-1371.

Hallman DM, Boerwinkle E, Saha N, Sanholzer C, Menzel HJ, Csazar A \& Utermann G (1991) The apolipoprotein E polymorphism: a comparison of allele frequencies and effects in nine populations. American Journal of Human Genetics 49 , 338-349.

Harjai KJ (1999) Potential new cardiovascular risk factors: Left ventricular hypertrophy, homocysteine, lipoprotein(a), triglycerides, oxidative stress, and fibrinogen. Annals of Internal Medicine 131, 376-386.

LaRosa JC, Hunninghake D, Bush D, Criqui MH, Getz GS, Gotto AM, Grundy SM, Rakita L, Robertson RM, Weisfeldt ML \& Cleeman JI (1990) The cholesterol facts. A summary of the evidence relating dietary fats, serum cholesterol, and coronary 
heart disease: A joint statement by the American Heart Association and the National Heart, Lung, and Blood Institute. Circulation 81, 1721-1733.

Linn S, Carroll M, Johnson C, Fulwood R, Kalsbeek W \& Briefel R (1993) High-density-lipoprotein cholesterol and alcohol consumption in United States white and black adults - Data from NHANES-II. Am J Publ Health 83, 811-816.

Loktionov A, Bingham SA, Vorster H, Jerling JC, Runswick SA \& Cummings JH (1998) Apolipoprotein E genotype modulates the effect of black tea drinking on blood lipids and blood coagulation factors: a pilot study. British Journal of Nutrition 79, $133-139$.

Loktionov A, Vorster H, O'Neill IK, Nell T, Bingham SA, Runswick SA \& Cummings JH (1999) Apolipoprotein E and methylenetetrahydrofolate reductase genetic polymorphisms in relation to other risk factors for cardiovascular disease in UK Caucasians and Black South Africans. Atherosclerosis 145, $125-135$.

Mayer EJ, Newman B, Quesenberry CP, Friedman GD \& Selby JV (1993) Alcohol consumption and insulin concentrations - Role of insulin in associations of alcohol intake with high-densitylipoprotein cholesterol and triglycerides. Circulation 88, 21902197.

McGill HC (1979) The relationship of dietary cholesterol to serum cholesterol concentration and to atherosclerosis in man. American Journal of Clinical Nutrition 32, 2664-2702.

Muntwyler J, Hennekens CH, Buring JE \& Gaziano JM (1998) Mortality and light to moderate alcohol consumption after myocardial infarction. Lancet 352, 1882-1885.

Pasagian-Macaulay A, Aston CE, Ferrell RE, McAllister AE, Wing RR \& Kuller LH (1997) A dietary and behavioral intervention designed to lower coronary heart disease. Risk factors are unaffected by variation at the APOE gene locus. Atherosclerosis 132, 221-227.

Patsch JR (1993) Is hypertriglyceridemia atherogenic? Atherosclerosis Reviews 25, 331-339.

Report of the Panel on Dietary Reference Values of the Committee on Medical Aspects of Food Policy (COMA)
(1991) Dietary Reference Values for Food Energy and Nutrients for the United Kingdom. Report on Health and Social Subjects 41, Department of Health. HMSO: London.

Report of the Cardiovascular Review Group of the Committee on Medical Aspects of Food Policy (COMA) (1994) Nutritional Aspects of Cardiovascular Disease. Report on Health and Social Subjects 46, Department of Health. HMSO: London.

Ross R (1993) The pathogenesis of atherosclerosis: a perspective for the 1990s. Nature 362, 801-809.

Sarkkinen E, Korhonen M, Erkkilä , Ebeling T \& Uusitupa M (1998) Effect of apolipoprotein E polymorphism on serum lipid response to the separate modification of dietary fat and dietary cholesterol. American Journal of Clinical Nutrition 68, 12151222.

Savolainen MJ, Rantala M, Kervinen K, Jarvi L, Suvanto K, Rantala T \& Kesaniemi YA (1991) Magnitude of dietary effects on plasma cholesterol concentration: role of sex and apolipoprotein E phenotype. Atherosclerosis 86, 145-152.

Thun MJ, Peto R, Lopez AD, Monaco JH, Henley SJ, Heath CW \& Doll R (1997) Alcohol consumption and mortality among middle-aged and elderly US adults. New England Journal of Medicine 337, 1705-1714.

Tikkanen MJ, Huttunen JK, Ehnholm C \& Pietinen P (1990) Apolipoprotein E4 homozygosity predisposes to serum cholesterol elevation during high fat diet. Arteriosclerosis 10, 285288.

Weisgraber KH \& Mahley RW (1996) Human apolipoprotein E: The Alzheimer's disease connection. FASEB Journal 10, 14851494.

Wilson PF, Myers RH, Larson MH, Ordovas JM, Wolf PA \& Schaefer EJ (1994) Apolipoprotein E alleles, dyslipidemia and coronary heart disease. The Framingham Offspring Study. JAMA 272, 1666-1671.

Wilson PWF, Schaeffer EJ, Larson MG, Ordovas JM, (1996) Apolipoprotein-e alleles and risk of coronary disease - a metaanalysis. Arteriosclerosis, Thrombosis and Vascular Biology 16, 1250-1255. 